\title{
Determination of Kinetic Parameters in the interaction between Hydrogen Peroxide and Chromium (VI) Oxide
}

\author{
${ }^{1}$ Abdu M.S., ${ }^{2}$ Faruq U.Z., ${ }^{3}$ Aska, A.S, ${ }^{4}$ Dangoggo S.M. and ${ }^{5}$ Baraya K. A. \\ ${ }^{1,3 \& 5}$ Department of Chemistry, Aminu Saleh College of Education Azare, Bauchi State, Nigeria \\ ${ }^{2 \& 4}$ Department of Pure and Applied Chemistry, Usman Danfodio University Sokoto, Nigeria.
}

\begin{abstract}
The kinetics of the interaction between Chromium (vi) Oxide and Hydrogen Peroxide were studied. Hydrogen Peroxide is marketed in the form of an aqueous solution and being a limiting reagent in this research, its concentration was first determined by titration with standard solution of Potassium Permanganate $(0.02 M)$ before its subsequent utilization. The effect of varying mass of $\mathrm{CrO}_{3}$ on the decomposition of fixed volume of $\mathrm{H}_{2} \mathrm{O}_{2}$ was studied by measuring the volume of oxygen evolved and the time taken for the evolution to cease. Similarly, the effect of the decomposition of varying volumes of $\mathrm{H}_{2} \mathrm{O}_{2}$ with fixed mass of $\mathrm{CrO}_{3}$ was also studied. At the end of the reaction, the volume of $\mathrm{O}_{2}$ evolved and the time taken for the evolution of $\mathrm{O}_{2}$ were equally recorded. The results of the above decompositions indicated that $\mathrm{CrO}_{3}$ acted as a catalyst. The decomposition of $\mathrm{H}_{2} \mathrm{O}_{2}$ catalyzed by $\mathrm{CrO}_{3}$ was found to be a first order reaction. This was determined through the measurement of the half-life of the same reaction. The results of the titrations of acidified solution of $\mathrm{H}_{2} \mathrm{O}_{2}$ against $\mathrm{KMnO}_{4}$ solution at different time intervals carried out at $35^{\circ} \mathrm{C}$ and $45^{\circ} \mathrm{C}$ were used in calculating the specific rate constants and were found to be $3.11 \times 10^{-2}$ and $6.11 \times 10^{-2}$ respectively. Furthermore, the values of the specific rate constants obtained were used in calculating the activation energy of the reaction $\left(E_{a}\right)$ which was found to be $13.49075 \mathrm{kcal}$.
\end{abstract}

Keywords: Determination, Kinetic parameters, Hydrogen peroxide, Chromium (vi) Oxide.

\section{Introduction}

Since chemical kinetics is the study of reaction rates, factors that affect rates and reaction mechanisms, everyone is affected by reaction kinetics in one way or the other. This is because if reactions had proceeded swiftly or evenly at the same rate towards the equilibrium, the universe would have been less than what it is. The major application of chemical kinetics is the elucidation of reaction mechanism, which is the sequence of steps by which the reactants are converted to products. The reaction rate law which must be determined experimentally provides us with a clue to the reaction mechanism, understanding of which enables one to adjust reaction conditions. In chemical manufacturing, which constitutes the most important aspect of chemical engineering, reaction kinetics plays a vital role especially in organic synthesis where several possible competing reactions can occur. The relative rates of these reactions usually influence the yield of each product. Thus experimental conditions must be adjusted to maximize the yield of the desired product (Raymond,1977). Chemical kinetics is also applied in the determination and control of the stability of commercial products such as pharmaceutical dosage, foams, food, paints and metal (Raymond, 1977). Although both hydrogen peroxide and chromium (vi) oxide are oxidizing agents, however, chromium (vi) oxide being the oxide of a transition metal is assumed to catalyze the decomposition of hydrogen peroxide during their interaction as proposed in the following equation:

$$
2 \mathrm{H}_{2} \mathrm{O}_{2} \stackrel{\mathrm{CrO}_{3}}{\longrightarrow} 2 \mathrm{H}_{2} \mathrm{O}+\mathrm{O}_{2} \ldots \ldots \ldots \ldots \ldots \ldots \ldots \ldots \ldots \ldots \ldots \ldots \ldots \ldots \ldots \ldots \ldots
$$

Hydrogen peroxide is probably a unique chemical, ideally suited to the present age where environmental considerations are always to the fore. Firstly, it is capable of diverse chemistry it could act as either an oxidizing or reducing agent. As an oxidizing agent, its application ranges from highly selective oxidization chemistry applicable to the manufacture of many organic compounds through the bleaching of pulp, total oxidation of large organic compounds to carbon dioxide. Its reactivity is largely controlled by the ratio of the concentration of hydrogen peroxide to the substrate and the reaction conditions particularly the choice of catalyst and factors such as UV irradiation (Sieracki, 1986). Secondly, it is a strong oxidizing agent that may be formed by cathodic reduction under mild and varied conditions, opening up the possibility of producing the same product at both anode and cathode. It is environmentally friendly because its reactions leave no residue in the reaction stream and it may be manufactured from only air and electricity as feed stocks. In addition, when used in dilute solutions such as those produced in electrolytic cells, its reactions are non-hazardous and are carried out under very moderate conditions. Chromium (vi) oxide is a strong oxidizing agent both in acid and when dissolved in water. Typically, reactions with combustibles, flammables, other reducing agents and with 
bases are rapid and violent. Sometimes, explosive and often resulting in fires that is difficult to extinguish. This compound decomposes when heated (usually above $250^{\circ} \mathrm{C}$ ) forming the trivalent oxide and oxygen as shown in equation 1.2

$$
4 \mathrm{CrO}_{3} \longrightarrow 2 \mathrm{Cr}_{2} \mathrm{O}_{3}+3 \mathrm{O}_{2} \ldots \ldots \ldots \ldots \ldots \ldots \ldots \ldots \ldots \ldots .2
$$

The interaction of Chromium (vi) oxide with organic substances is vigorous and may be explosive (Young, 2003a). However, Chromium (vi) oxide is widely used in both organic and inorganic chemistry as an oxidant. For example, oxidation of secondary alcohols using tripropylammonium fluorochromate in dichloromethane to ketone (Ghammany, 2004) as shown in the equation 1.3

\section{$\mathrm{R}^{1} \mathrm{R}^{2} \mathrm{CH}-\mathrm{OH} \longrightarrow \mathrm{R}^{1} \mathrm{R}^{2} \mathrm{C}=\mathrm{O} \ldots \ldots \ldots \ldots \ldots \ldots . . . \ldots \ldots$}

Typical symptoms of atomic exposures to Chromium (vi) oxide include severs skin burns. In the eyes, pain, blurred vision and blindness result. If inhaled, sore throat, coughing, labored breathing, lung edma are experienced. If ingested, abdominal spasm, vomiting and diarrhea occur (Young, 2003b).

The knowledge of chemical kinetics in the interaction of the reactants under consideration will provide the idea of reaction rates, factors affecting the rate of reaction and the reaction mechanisms of their individual reactions with other substances. Hydrogen peroxide is selected for this research because of its availability, cost, safety and field experience in its use than permanganate. Hydrogen peroxide is incompatible with many substances that catalyze its decomposition, including most of the transition metals and their compounds but Chromium (vi) oxide decomposes it vigorously to release oxygen. Despite numerous research studies, there still many uncertainties with regard to the kinetics and reaction mechanism of interaction between Chromium (vi) oxide and Hydrogen peroxide. However the use of buffers which provides relatively limited $\mathrm{pH}$ range in which several studies were conducted makes the results less applicable for industrial purposes. Therefore, this study was carried out to investigate the kinetics of the interaction between Chromium (vi) Oxide and Hydrogen peroxide as a prelude to their combined oxidation system on Organic substances.

\section{Materials And Methods}

Samples: Hydrogen peroxide and Chromium (vi) Oxide

Apparatus and the reagents used are Burette, Conical flask, Beakers, Buckner flasks, delivery tube, measuring cylinder, stop watch, syringes, trough, tripod stand and clip, $0.2 \mathrm{M} \mathrm{H}_{2} \mathrm{SO}_{4}, 0.05 \mathrm{M}$ Potassium permanganate, common salt, distilled water. The samples and reagents utilized were all analytical grade.

\section{Standardization of potassium permanganate}

The potassium permanganate $\left(\mathrm{KMnO}_{4}\right)$ solution was standardized using the procedure recommended by Vogel (Mendham et al, 2000a),that is $0.3 \mathrm{~g}$ of dry sodium oxalate was weighed and transferred into $600 \mathrm{ml}$ beaker followed by the addition of $240 \mathrm{ml}$ distilled water. Also $12.5 \mathrm{ml}$ of concentrated sulphuric acid was added and content was allowed to cool to room temperature to ensure absolute dissolution of sodium oxalate. The mixture was then titrated with $90-95 \%$ permanganate solution in the burette at the rate of $25-35 \mathrm{ml}$ per min. The content was heated to $55-60^{\circ} \mathrm{C}$ (thermometer and stirring rod were used). The titration was completed by adding permanganate solution until a faint pink color persists for $30 \mathrm{sec}$. The titration was repeated twice. Below is the equation for the reaction:

$$
2 \mathrm{Na}^{+}+\mathrm{C}_{2} \mathrm{O}_{4}{ }^{2-}+2 \mathrm{H}^{+} \rightleftarrows \mathrm{H}_{2} \mathrm{C}_{2} \mathrm{O}_{4}+2 \mathrm{Na}^{+}
$$

\section{Determination of the concentration of Hydrogen Peroxide}

The procedure described by Vogel (Mendham et al, 2000b) was used to determine the concentration of Hydrogen peroxide. $25.00 \mathrm{~cm}^{3}$ of $\mathrm{H}_{2} \mathrm{O}_{2}$ was measured and transferred into $500 \mathrm{ml}$ graduated flask and diluted with distilled water up to the mark. The solution was shaken thoroughly to ensure absolute dilution. $25 \mathrm{~cm}^{3}$ of this solution was pipetted out and transferred into a conical flask. This solution was further diluted with $200 \mathrm{ml}$ of distilled water, followed by the addition of $20 \mathrm{ml}$ of dilute sulphuric acid (1:5) and titrated against $0.02 \mathrm{M}$ solution of $\mathrm{KMnO}_{4}$ to the first permanent, faint pink colour. The titration was repeated twice to ensure accurate end point.

\section{Effect of varying mass of $\mathrm{CrO}_{3}$ on the decomposition of fixed volume of $\mathrm{H}_{2} \mathrm{O}_{2}$}

Ten milligrams $\left(10 \mathrm{mg}\right.$ ) of Chromium (vi) oxide was placed in a $250 \mathrm{~cm}^{3}$ conical flask in a set-up method adapted from the procedure for collection and measuring of volume of biogas (Dangoggo, 2004). The set-up consist of a $250 \mathrm{~cm}^{3}$ Buckner flask corked with a rubber bung and a $50 \mathrm{~cm}$ PVC rubber tube fitted to the side arm of the Buckner flask. The free end of the PVC tube was placed into an inverted measuring cylinder 
filled with saline water in a trough. $10.00 \mathrm{~cm}^{3}$ of $\mathrm{H}_{2} \mathrm{O}_{2}$ was injected into the flask and stop watch was switched on. The time taken for the evolution of oxygen to cease and volume of oxygen generated were recorded. The same procedure was repeated with 20,30,40, 50, and 60mg of $\mathrm{CrO}_{3}$ keeping the volume of $\mathrm{H}_{2} \mathrm{O}_{2}$ constant at $10.00 \mathrm{~cm}^{3}$.

Effect of fixed mass of $\mathrm{CrO}_{3}$ on the decomposition of varying volumes of $\mathrm{H}_{2} \mathrm{O}_{2}$

The above procedure was repeated with fixed mass of Chromium (vi) oxide (10mg) and Varying volumes of $\mathrm{H}_{2} \mathrm{O}_{2}$ starting from $10,20,30,40,50$ and $60 \mathrm{~cm}^{3}$. The time taken for the evolution of $\mathrm{O}_{2}$ to cease and the volume of $\mathrm{O}_{2}$ evolved were recorded.

\section{Results}

The results of the analysis were presented in the tables below:

Table 1a: The result of the decomposition of constant volume of $\mathrm{H}_{2} \mathrm{O}_{2}$ by Varying mass of $\mathrm{CrO}_{3}$

\begin{tabular}{|l|c|c|c|c|}
\hline S/No. & Mass of $\mathrm{CrO}_{3}(\mathrm{mg})$ & Volume of $\mathrm{H}_{2} \mathrm{O}_{2}\left(\mathrm{~cm}^{3}\right)$ & Volume of $\mathrm{O}_{2}$ evolved $\left(\mathrm{cm}^{3}\right)$ & Time $(\mathrm{sec})$. \\
\hline 1 & 10 & 10 & 730 & 245 \\
\hline 2 & 20 & 10 & 728 & 144 \\
\hline 3 & 30 & 10 & 730 & 125 \\
\hline 4 & 40 & 10 & 730 & 61 \\
\hline 5 & 50 & 10 & 730 & 34 \\
\hline 6 & 60 & 10 & 730 & 23 \\
\hline
\end{tabular}

Table 1b: The Result of the decomposition of Varying Volumes of $\mathrm{H}_{2} \mathrm{O}_{2}$ by fixed mass of $\mathrm{CrO}_{3}$

\begin{tabular}{|c|c|c|c|c|}
\hline S/No. & $\mathrm{MassofCrO}_{3}(\mathrm{mg})$ & Volume of $\mathrm{H}_{2} \mathrm{O}_{2}\left(\mathrm{~cm}^{3}\right)$ & Volume of $\mathrm{O}_{2}$ evolved $\left(\mathrm{cm}^{3}\right)$ & Time(sec.) \\
\hline 1 & 10 & 10 & 730 & 245 \\
\hline 2 & 10 & 20 & 1452 & 281 \\
\hline 3 & 10 & 30 & 2187 & 330 \\
\hline 4 & 10 & 40 & 2925 & 362 \\
\hline 5 & 10 & 50 & 3650 & 461 \\
\hline 6 & 10 & 60 & 4380 & 483 \\
\hline
\end{tabular}

Table 2: The Result of the measurement of half-life from the decomposition of Varying Volumes of $\mathrm{H}_{2} \mathrm{O}_{2}$ by fixed mass of $\mathrm{CrO}_{3}$

\begin{tabular}{|c|c|c|c|c|}
\hline S/No. & Mass of $\mathrm{CrO}_{3}(\mathrm{mg})$ & Volumeof $\mathrm{H}_{2} \mathrm{O}_{2}\left(\mathrm{~cm}^{3}\right)$ & Half-life(Time /sec) & Order of Reaction \\
\hline 1 & 10 & 10 & 120 & - \\
\hline 2 & 10 & 20 & 140 & 0.80 \\
\hline 3 & 10 & 30 & 165 & - \\
\hline 4 & 10 & 40 & 180 & 0.70 \\
\hline 5 & 10 & 50 & 230 & - \\
\hline 6 & 10 & 60 & 240 & 0.86 \\
\hline
\end{tabular}

Table 3a: The Result of the titration of acidified solution of $\mathrm{H}_{2} \mathrm{O}_{2}$ against $\mathrm{KMnO}_{4}$ solution at different time intervals carried out at $35^{\circ} \mathrm{C}$

\begin{tabular}{|l|c|c|l|}
\hline S/No. & Time (min.) & $\begin{array}{c}\text { Volume of } \mathrm{KMnO}_{4} \text { used for } 10 \mathrm{~cm}^{3} \text { of } 0.2 \mathrm{M} \\
\mathrm{H}_{2} \mathrm{SO}_{4}\left(\mathrm{~cm}^{3}\right)\end{array}$ & Specific rate constant $(\mathrm{K}) \times 10^{-2}$ \\
\hline 1 & 0 & 50.00 & - \\
\hline 2 & 10 & 33.80 & 3.11 \\
\hline 3 & 20 & 25.00 & 3.11 \\
\hline 4 & 30 & 18.20 & 3.11 \\
\hline
\end{tabular}

Table 3b: The Result of the titration of acidified solution of $\mathrm{H}_{2} \mathrm{O}_{2}$ against $0.02 \mathrm{M} \mathrm{KMnO}_{4}$ solution at different time intervals carried out at $45^{\circ} \mathrm{C}$

\begin{tabular}{|c|l|c|l|}
\hline S/No. & Time (min.) & Volume of $\mathrm{KMnO}_{4}$ used for $10 \mathrm{~cm}^{3}$ of $0.2 \mathrm{M} \mathrm{H}_{2} \mathrm{SO}_{4}\left(\mathrm{~cm}^{3}\right)$ & Specific rate constant $(\mathrm{K}) \times 10^{-2}$ \\
\hline 1 & 0 & 22.50 & - \\
\hline 2 & 10 & 12.25 & 6.11 \\
\hline 3 & 20 & 6.50 & 6.11 \\
\hline 4 & 30 & 3.50 & 6.12 \\
\hline
\end{tabular}

Determination of Activation Energy (Ea):

The following equation was used in calculating activation energy:

$\log \mathrm{k}_{2} / \mathrm{k}_{1}=\mathrm{Ea} / 2.303 \mathrm{R}\left[\mathrm{T}_{2}-\mathrm{T}_{1} / \mathrm{T}_{1} \mathrm{~T}_{2}\right] \ldots \ldots \ldots \ldots \ldots \ldots . \ldots$

Where: $\mathrm{k}_{1}=3.11 \times 10^{-2}$ obtained from table $3 \mathrm{a}, \mathrm{K}_{2}=6.21 \times 10^{-2}$ obtained from table $3 \mathrm{~b}$ $\mathrm{T}_{1}=35^{\circ} \mathrm{C}+273 \mathrm{~K}=308 \mathrm{~K}, \mathrm{~T}_{2}=45^{\circ} \mathrm{C}+273 \mathrm{~K}=318 \mathrm{~K}, \mathrm{R}=$ Gas constant $\left(1.987 \mathrm{cal} \mathrm{K}^{-1} \mathrm{~mol}^{-1}\right)$

$\mathrm{Ea}=$ Activation energy.

On substituting the values in equation (4), Ea was found to be $13.49075 \mathrm{kcal}$ 


\section{Discussions}

Effort was made to ascertain the source of oxygen from the interaction of the two powerful oxidizing agents mentioned above. Table 1a shows that the oxygen released came exclusively from $\mathrm{H}_{2} \mathrm{O}_{2}$ with no contribution from $\mathrm{CrO}_{3}$. This is because the volume of the oxygen released remained virtually the same in spite of the steady increase in the quantity of $\mathrm{CrO}_{3}$. This result agreed with the decomposition of $\mathrm{H}_{2} \mathrm{O}_{2}$ catalyzed by $\mathrm{CrO}_{3}$ as shown in equation 1.1. If there is any contribution of the oxygen released from $\mathrm{CrO}_{3}$ the volume of the $\mathrm{O}_{2}$ released would have increased with the increase in the amount of $\mathrm{CrO}_{3}$. The equation for the interaction would have been represented as follows:

$$
4 \mathrm{CrO}_{3}+2 \mathrm{H}_{2} \mathrm{O}_{2} \longrightarrow 2 \mathrm{Cr}_{2} \mathrm{O}_{3}+2 \mathrm{H}_{2} \mathrm{O}_{2}+4 \mathrm{O}_{2} \ldots \ldots \ldots \ldots \ldots \ldots \ldots \ldots \ldots \ldots
$$

This further supported the argument that the oxygen released during the interaction is only coming from the $\mathrm{H}_{2} \mathrm{O}_{2}$ alone. It was also noticed that the time for the completion of the reaction decreases with every increase in the amount of $\mathrm{CrO}_{3}$. This is actually expected because increase in the amount of $\mathrm{CrO}_{3}$ brings about more contact with $\mathrm{H}_{2} \mathrm{O}_{2}$ and hence faster decomposition. The result of varying volumes of $\mathrm{H}_{2} \mathrm{O}_{2}$ with fixed quantity of $\mathrm{CrO}_{3}$ in table $1 \mathrm{~b}$ also supported the idea that the Oxygen released during the interaction solely came from $\mathrm{H}_{2} \mathrm{O}_{2}$ only. This is because there was a steady increase in the volume of $\mathrm{O}_{2}$ evolved with increase in the volume of $\mathrm{H}_{2} \mathrm{O}_{2}$. Similarly, an increased in the volumes of Oxygen evolved with increase in the volume of Hydrogen peroxide indicated that the volume of Oxygen evolved is a function of the volume of Hydrogen peroxide. It was also observed that the time for the completion of the reaction is directly proportional the volume of Hydrogen peroxide. Table 2 shows a steady increase in the half-life of the reaction time with increase in the volume of $\mathrm{H}_{2} \mathrm{O}_{2}$ at constant mass of $\mathrm{CrO}_{3}$. This also supported the argument that Oxygen released came from $\mathrm{H}_{2} \mathrm{O}_{2}$ while $\mathrm{CrO}_{3}$ only catalyzed its decomposition. When fixed mass of $\mathrm{CrO}_{3}$ interacted with various volumes of $\mathrm{H}_{2} \mathrm{O}_{2}$, the data generated was used in calculating order of the reaction (n) with the help of the following equation:

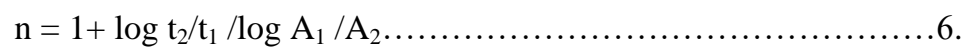

The result obtained is presented in table 2 above.

The results of titrations of acidified solutions of $\mathrm{H}_{2} \mathrm{O}_{2}$ with a solution of $\mathrm{KMnO}_{4}$ at various times intervals carried out at $35^{\circ} \mathrm{C}$ and $45^{\circ} \mathrm{C}$ were used in calculating specific rate constant $(\mathrm{k})$ using the following equation:

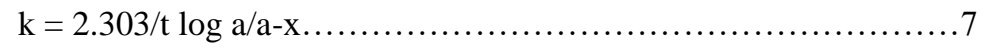

The data generated and results obtained are tabulated in tables $3 \mathrm{a}$ and $\mathrm{b}$ above. From the data generated and the results obtained activation energy (Ea) was calculated using equation 4 above. The specific rate constants for the interaction were found to be $3.11 \times 10^{-2}$ at $35^{\circ} \mathrm{C}$ and $6.12 \times 10^{-2}$ at $45^{\circ} \mathrm{C}$. Similarly, the activation energy for the interaction was found to be $13.49075 \mathrm{kcal}$.

\section{Conclusion}

During the interaction, it was confirmed that $\mathrm{H}_{2} \mathrm{O}_{2}$ is the limiting reagent and $\mathrm{CrO}_{3}$ catalyzed its decomposition. Decrease in the reaction time with increase in $\mathrm{CrO}_{3}$ confirmed the role of $\mathrm{CrO}_{3}$ as a catalyst. The decomposition of $\mathrm{H}_{2} \mathrm{O}_{2}$ was found to be a first order reaction. Increased in specific rate constant and activation energy with increase in temperature supported the fact that increase in temperature increases the rate of a reaction.

\section{Acknowledgement}

The Authors wish to acknowledge the management of Aminu Saleh College of Education, Azare for providing us with an equipped laboratory without which the research would not have been possible. We also wish to appreciate the effort of Laboratory assistant and technicians from the beginning of the research up to its conclusion.

\section{References}

[1]. Bahl A., Bahl B.S and Tuli G.D.(2012): Essentials of Physical Chemistry. S. Chand \&Company LTD, Ram Nagar New Delhi. Rev. edn Pp. 844-846.

[2]. Dangoggo S.M., Sambo, A.S. and Zuru A.A. (2004): Biogas production from cattles, camels and donkeys dung Nigerian Journal of Renewable Energy, Vol. 12 No. 1\&2 Pp.7-11.

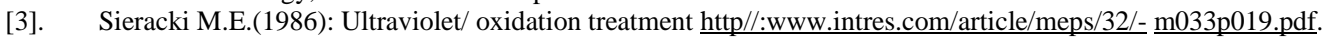

[4]. Ghammany D.E. (2004): Oxidation of Alcohols. Bull. Korea Chem. Soc. Vol.25 No.8 Pp. 1277

[5]. Mendham J., Denney R.C, Barnes J.D. and Thomas M.J.K. (2000a): Vogel's textbook of Quantitative chemical analysis, $6^{\text {th }}$ edn Prentice Hall U.K, p420

[6]. Mendham J. Denney R.C., Barnes J.D. and Thomas M.J.K (2000b): Vogel's textbook of Quantitative Chemical analysis, $6^{\text {th }}$ edn Prentice Hall UK, p127.

[7]. Wong Y.C., Wong CT., Onyiruka S.O and Akpanisi L.E (2002): University General Chemistry. Africana Fep Publishers LTD. 14 Zaria road Jos, Plataeu State Nigeria. $1^{\text {st }}$ edn Pp 336-340.

[8]. Young J.A. (2003a): Hazardous characteristics of Chromium (vi) oxide. Journal of Chem. Education Vol. 80, No. 3 Pp.116.

[9]. Young J.A. (2003b): Hazardous characteristics of Chromium (vi) oxide. Journal of Chem. Education. Vol. 80, No. 3 pp118. 